\title{
Impact of Coronavirus Lockdown on Preterm Deliveries
}

\section{Rafia Gul $^{1 *}$, Mussab Ahmad ${ }^{1}$, Zahid Anwar ${ }^{1}$, Fouzia Ishaq ${ }^{2}$, Furqan Saleemn ${ }^{1}$ and Faiza Yaseen ${ }^{1}$}

${ }^{1}$ Department of Neonatology, Fatima Memorial Hospital, Lahore, Pakistan

${ }^{2}$ Sir Ganga Ram Hospital, Lahore, Pakistan

*Corresponding Author: Rafia Gul, Department of Neonatology, Fatima Memorial

Hospital, Lahore, Pakistan.
Received: February 19, 2021

Published: March 12, 2021

(C) All rights are reserved by Rafia Gul., et al.

\begin{abstract}
Introduction: The COVID- 19 global pandemic has impacted all domains of our sphere. WHO recommended mitigation measures to avoid its spread and lock down was one of these. The impact of lock down on perinatal period has been elucidated in different settings. During lockdown period, a varied outcome has been reported as, reduction in number of premature birth, an increase in still births as well and reduction in child birth rate. To our knowledge, such local data is lacking. We wished to study this impact in resource limited country.

Objective of this Study: To document the impact of Corona-Virus lockdown on preterm deliveries.

Methodology: A retrospective cohort study was conducted in Fatima Memorial Hospital, Lahore, Pakistan. Data of live births was collected from Fatima Memorial Hospital and Sir Ganga-Ram Hospital, Lahore, Pakistan. Analysis for live births using Microsoft Excel to calculate total number and percentages for all term and preterm deliveries (34-36+6 weeks, 28-33+6 weeks and less than 28 weeks) during Corona Virus lockdown calendar months (March - August) in 2020, 2018, 2019 and mean of aggregated period 2018-19. We calculated $\mathrm{p}$ value odd ratio (OR) and 95\% confidence intervals for comparable gestation groups. The $\mathrm{p}$ value $<0.05$ was considered statistically significant.

Results: There were 37679 live births at FMH and SGRH from March to August calendar months during 2018 - 20. Data analysis shows that statistically significant number of preterm were born in 2020 as compared to mean of this aggregated period (2018-19) at FMH ( $\mathrm{p}=0.015$, OR 0.86 and 95\% CI $0.85-0.88$ ), SGRH ( $\mathrm{p}=0.00$, OR 1.23 and $05 \%$ CI $1.22-1.24$ ) and for combined data as well ( $\mathrm{p}=$ 0.00 , OR 1.19 and 95\%CI 0.89 - 0.93). Moreover, neonates born at gestational age $<28$ weeks was statistically significant as compared to mean of aggregated period as FMH ( $\mathrm{p}=0.00$, OR 1.92 and 95\% CI $1.72-3.05$ ), SGRH ( $\mathrm{p}=0.04$, OR 1.42 and $05 \%$ CI $1.34-1.98$ ) and for combined data as well ( $\mathrm{p}=0.00$, OR 1.36 and 95\%CI $1.31-1.79$ ) (Table 2).

Conclusion: During corona virus lockdown 2020 (March - August) an incremental trend towards preterm deliveries (17\%) especially of gestational age $<28$ weeks (about $57 \%$ ) has been documented. Possible link between premature birth and antenatal care during lock don period require further research.
\end{abstract}

Keywords: COVID-19; Preterm; Antenatal Care; Lockdown; Pregnancy

\section{Abbreviations}

FMH: Fatima Memorial Hospital; SGRH: Sir Ganga Ram Hospital

\section{Introduction}

The COVID- 19 global health emergency, caused by SARS-CoV-2, has impacted all domains of our sphere [1]. WHO recommended 
mitigation measures to avoid its spread and lock down was one of these measures which were universally followed [2].

In Pakistan, first case was reported on $26^{\text {th }}$ February 2020 in Karachi. In continuum of WHO COVID crisis policy, Government of Pakistan implemented lockdown at national level from March 2020 till August 2020.

Social isolation or lockdown transformed all walks of life by defining new "normal" including health sector.

Globally, health possessions were redirected towards COVID outbreak while restricting non-emergency cases. A lot of research is going on regarding the influence of this restricted access to medical facilities on patient community.

The concerns regarding impact of lock down on perinatal period have been elucidated in different settings $[3,4]$. Data from developed countries show reduction in number of premature birth during lockdown period [5]. Still there are studies showing an overall reduction in child birth rate [6]. On the other hand, it is believed that lock down has resulted preterm in interruption of access to medical facilities and antenatal care for pregnant females This situation has been observed more frequently in resource limited countries and has resulted in rise in still birth and mortality [7].

Prematurity (live birth before 37 weeks of gestation) burden is growing like a snowball. It is a leading cause of under-five mortality. According to WHO, 2019 statistics showed that 47\% of under 5 mortality was contributed by neonatal mortality [8]. Pakistan ranks among top 6 countries which contribute to $50 \%$ of total preterm births worldwide. Pakistan's pre-corona lockdown statistics show that preterm cobstitute $15.8 \%$ of all deliveries [9].

To our knowledge, data about premature births in poor socioeconomic countries is lacking. We wished to study impact of corona virus lock down on rate of premature birth in our settings (both government and private), which are the tertiary care centers in resource limited country.

\section{Materials and Methods}

A retrospective cohort study was conducted in Fatima Memorial Hospital. Data was collected from 2 leading hospitals in Lahore including Fatima Memorial Hospital (FMH, private sector) and Sir Ganga-Ram Hospital (SGRH, government sector). We recorded all live births during COVID-19 lockdown months i.e. March to August in 2020 and during same calendar months in 2018 and 2019 taken as reference period.

Microsoft Excel was used for statistical analysis. Data in form of numbers and percentages was categorized according to gestation age. Preterm births were further subcategorised as less than 28 weeks, 28-33+6 weeks and 34-36+6 weeks.

For each gestational age category, mean value for reference period (March to August 2018 and 2019) was calculated. The p value, odd ratio (OR) and $95 \%$ confidence intervals (95\% CI) were used to calculate changes in proportion of gestational age at birth categories between the lockdown period and the mean value for reference period. The $p$ value $<0.05$ was considered statistically significant.

\section{Results and Discussion}

Results

There were total 37679 live births at FMH and SGRH in calendar months March to August during 2018 - 20. Among these, 5403 live births were from FMH and 32276 were delivered at SGRH. Gestational age based neonatal data in form of number and percentages have been shown in table 1.

The $\mathrm{p}$ value, odd ratio and 95\% confidence interval demonstrated that statistically significant number of preterm were born during lock down period in FMH ( $p=0.015)$, SGRH $(p=0.00)$ and combined data $(\mathrm{p}=0.00)$ (Table 2).

During lockdown period, a rise of $17 \%$ in preterm delivery and $57 \%$ in neonates delivered at gestational age $<28$ weeks as compared to mean of aggregated reference period (years 2018 - 19) has been observed.

Statistically significant proportion was of neonates were of gestation age $<28$ weeks during lock down period in FMH ( $p=0.00)$, SGRH ( $p=0.04$ ) and combined data $(p=0.03)$ (Table 2). While no differences in birth rates of preterm neonates of gestational age $28-33+6$ and $34-36+6$ were noted before and during lockdown (Table 2).

\section{Discussion}

The influence of COVID-19 pandemic has been observed far and wide. Under the recommendations by $\mathrm{WHO}$, as a preventive strategy for COVID-19, lock down (social isolation) was followed globally. In Pakistan it was implemented during March - August 2020. Research is going on to unfold the impact of lockdown on health sector including perinatal period. 


\begin{tabular}{|c|c|c|c|c|}
\hline Gestation age & $\begin{array}{c}\text { Year } 2018 \\
\text { n (\%) }\end{array}$ & $\begin{array}{c}\text { Year } 2019 \\
\text { n (\%) }\end{array}$ & $\begin{array}{c}\text { Mean of aggregated } \\
\text { reference period } \\
\text { (Years 2018 - 2019) } \\
n(\%)\end{array}$ & $\begin{array}{c}\text { Year } 2020 \\
\text { n (\%) }\end{array}$ \\
\hline \multicolumn{5}{|l|}{ FMH } \\
\hline$<28 \mathrm{wk}$ & $33(1.6 \%)$ & $34(1.7 \%)$ & $33.5(1.6 \%)$ & $41(3.1 \%)$ \\
\hline 28 to $33+6 \mathrm{wk}$ & $147(7.1 \%)$ & $144(7.2 \%)$ & $145.5(7.1 \%)$ & $108(8.2 \%)$ \\
\hline 34 to $36+6 \mathrm{wk}$ & $115(5.5 \%)$ & $105(5.2 \%)$ & $110(5.4 \%)$ & $79(6.0 \%)$ \\
\hline Term & $1785(85.8 \%)$ & $1719(85.9 \%)$ & $1752(85.8 \%)$ & $1093(82.7 \%)$ \\
\hline Total & $2080(100 \%)$ & $2002(100 \%)$ & $2041(100 \%)$ & $1321(100 \%)$ \\
\hline \multicolumn{5}{|l|}{ SGRH } \\
\hline$<28 \mathrm{wk}$ & $56(0.5 \%)$ & $72(0.6 \%)$ & $64(0.6 \%)$ & $78(0.8 \%)$ \\
\hline 28 to $33+6 \mathrm{wk}$ & $393(3.7 \%)$ & $576(4.8 \%)$ & $484.5(4.3 \%)$ & $525(5.4 \%)$ \\
\hline 34 to $36+6 \mathrm{wk}$ & $120(1.1 \%)$ & $155(1.3 \%)$ & $137.5(1.2 \%)$ & $107(1.1 \%)$ \\
\hline Term & $10122(94.7 \%)$ & $11139(93.3 \%)$ & $10630.5(93.9 \%)$ & $8933(92.6 \%)$ \\
\hline Total & $10691(100 \%)$ & $11942(100 \%)$ & $11316.5(100 \%)$ & $9643(100 \%)$ \\
\hline \multicolumn{5}{|c|}{ Combined data for both hospitals } \\
\hline$<28 \mathrm{wk}$ & $89(0.7 \%)$ & $106(0.8 \%)$ & $97.5(0.7 \%)$ & $119(1.1 \%)$ \\
\hline 28 to $33+6 \mathrm{wk}$ & $540(4.3 \%)$ & $720(5.1 \%)$ & $620(4.6 \%)$ & $633(5.8 \%)$ \\
\hline 34 to $36+6 \mathrm{wk}$ & $235(1.8 \%)$ & $260(1.9 \%)$ & $247.5(1.9 \%)$ & $186(1.7 \%)$ \\
\hline Term & 11907 (93.2\%) & $12858(92.2 \%)$ & $2382.5(92.7 \%)$ & $10026(91.4 \%)$ \\
\hline Total & $12771(100 \%)$ & $13944(100 \%)$ & $13357.5(100 \%)$ & $10964(100 \%)$ \\
\hline
\end{tabular}

Table 1: Gestational age based categories for neonatal data for study period.

Our study is till date only of its kind from developing country to determine the impact of COVID-19 lockdown on preterm births. While reference studies are limited in number and are from developed countries including Netherland, Denmark, Ireland and UK $[4,5,10,11]$.

Globally, in last couple of years, birth rate has shown a stepdown drift as 18.486 (2018), 18.282 (2019) and 18.077 (2020) respectively [12]. World population statistics show that birth rate remained unvaried during COVID-19 pandemic and lock down period. From 2018 onwards, an incremental trend in birth rate has been observed in Denmark and Netherland $0.87 \%$ and $0.2 \%$ respectively) $[13,14]$. However a declining trend has been observed in Ireland, Uk and Pakistan $(2.6 \%, 0.49 \%$ and $1.8 \%$ respectively) for the very same period [15-17]. In pre-corona era, 4 - 5\% of all births are premature in developed countries as compared to 15 $18 \%$ in Asia and Africa [4].
Data from Netherland shows that substantial reduction in preterm births occurred following introduction of COVID-19 mitigation measures nationwide [10]. Similarly, autonomous statistics from Denmark and Ireland showed significant drop in the birth rate of extremely preterm ( $<28$ weeks) as $90 \%$ and $73 \%$ respectively $[4,5]$. However, in United Kingdom, prevalence of prematurity was not affected by COVID pandemic and its mitigation measures [11]. On contrary to this, our scenario is quite different. We had statistically significant number of premature babies especially $<28$ weeks of gestation during lock down period. Now question arises that what is the actual reason behind all these figures.

Common risk factors of prematurity are maternal, fetal and environmental factors [18].

Our study just like other studies conducted in Netherland, Denmark, UK and Ireland have compared preterm births during lock down period with same calendar months in previous years in order to equate biological and environmental factors $[4,5,10,11]$. 


\begin{tabular}{|l|c|c|c|c|c|}
\hline Gestation & $\begin{array}{c}\text { Mean of } \\
\text { aggregated } \\
\text { reference } \\
\text { period } \\
\text { (Years 2018 } \\
\text { - 19) }\end{array}$ & $\begin{array}{c}\text { Year } \\
\mathbf{2 0 2 0}\end{array}$ & P value & OR & 95\% CI \\
\hline FMH & 33.5 & 41 & 0.00 & 1.92 & $1.72-3.05$ \\
\hline$<28$ wk & 145.5 & 108 & 0.26 & 1.16 & $1.12-1.20$ \\
\hline $\begin{array}{l}28 \text { to 33+6 } \\
\text { wk }\end{array}$ & 110 & 79 & 0.46 & 1.12 & $1.06-1.17$ \\
\hline 34 to 36+6 \\
wk
\end{tabular}

Table 2: $\mathrm{p}$ value, odd ratio (OR) and 95\% CI for preterm neonates.

Lockdown strategy proved really helpful in preventing disease spread. The infectivity rate curve of COVID-19 during lockdown flattened and this trend was followed in all countries including Netherland, Denmark, UK, Ireland and Pakistan [19,20].

Now the question arises that is it too early to be conclusive? Can we put this varied trend towards preterm births especially before 28 weeks of gestation under the umbrella of "lock down impact"? No doubt, lock down has changed our life style and way of thinking totally while creating new "normal". In presence of all other constant/ common factors in our study and other reference researches, we can think about a potential link between lock down and prematurity.

Researchers have proposed many "health promoting effect of COVID-19 lock-down" including improvements in ambient air quality, reductions in maternal stress and incidence of infections by improving hygienic measures in developed countries. In addition to this, continued standard antenatal services were available for pregnant mothers $[4,5,10]$. All these factors proved helpful to mothers to continue their pregnancy till term.

But the middle and low income countries lack of integrated health care delivery system and non-homogenous health facilities including antenatal health services. Muhaidat N., et al. in their study in Jordan, a middle income country, concluded that during lockdown period, changes in antenatal care provision and coverage have been observed and these may lead to pregnancy-related health problems [21]. In early 2020, Riley., et al. estimated that about $10 \%$ reduction in the provision of pregnancy-related health services in low- and middle-income countries during the COVID-19 outbreak could lead to a number of perinatal period related complications [22]. As reported by UNICEF, it was already feared that during lockdown period there shall be disruption in health delivery system and services including antenatal services [23].

On the basis of these facts, it can be speculated that, on one hand, antenatal services were not availed by pregnant mothers as they were reluctant to seek any kind of antenatal care with the fear that they might get infected. On the other hand, regular antenatal care services (non-emergency facilities) during lock down period were restricted. As a result many of pregnancy related medical conditions remained unattended and may be potential cause of preterm birth. This is all in accordance with what was feared and what research has shown [21-23].

On the basis of all these facts, figures and correlations, it can be speculated that our higher number of preterm births is not just by chance. This trend towards prematurity can be attributed to compromised antenatal services during lockdown period. However, further studies are required to establish such a relationship on strong grounds.

\section{Conclusion}

During corona virus lockdown 2020 (March - August) an incremental trend towards preterm deliveries $(17 \%)$ especially of gestational age $<28$ weeks (about $57 \%$ ) has been documented. Possible link between premature birth and antenatal care during lock don period require further research.

\section{Acknowledgements}

NA. 


\section{Conflict of Interest}

None.

\section{Bibliography}

1. Chen Huijun., et al. "Clinical Characteristics and Intrauterine Vertical Transmission Potential of COVID-19 Infection in Nine Pregnant Women: A Retrospective Review of Medical Records". The Lancet 395.10226 (2020): 809-815.

2. Green Janet., et al. "Exploring Modifiable Risk-Factors for Premature Birth in the Context of COVID-19 Mitigation Measures: A Discussion Paper". Journal of Neonatal Nursing (2020).

3. Kalyanasundaram Sridhar., et al. "Novel Corona Virus Pandemic and Neonatal Care: It's Too Early to Speculate on Impact!". SN Comprehensive Clinical Medicine 2.9 (2020): 1412-1418.

4. Philip Roy K., et al. "Unprecedented Reduction in Births of Very Low Birthweight (VLBW) and Extremely Low Birthweight (ELBW) Infants during the COVID-19 Lockdown in Ireland: A 'Natural Experiment' Allowing Analysis of Data from the Prior Two Decades". BMJ Global Health 5.9 (2020): e003075.

5. Hedermann Gitte., et al. "Danish Premature Birth Rates during the COVID-19 Lockdown". Archives of Disease in Childhood - Fetal and Neonatal Edition 106.1 (2020): 93-95.

6. KC Ashish., et al. "Effect of the COVID-19 Pandemic Response on Intrapartum Care, Stillbirth, and Neonatal Mortality Outcomes in Nepal: A Prospective Observational Study". The Lancet Global Health 8.10 (2020): e1273-1281.

7. Muhaidat Nadia., et al. "Pregnancy During COVID-19 Outbreak: The Impact of Lockdown in a Middle-Income Country on Antenatal Healthcare and Wellbeing". International Journal of Women's Health 12 (2020): 1065-1073.

8. "Newborns: improving survival and well-being".

9. Every preemie scale - Pakistan (2016).

10. Been Jasper V., et al. "Impact of COVID-19 Mitigation Measures on the Incidence of Preterm Birth: A National Quasi-Experimental Study". The Lancet Public Health 5.11 (2020): e604-611.

11. Khalil Asma., et al. "Change in the Incidence of Stillbirth and Preterm Delivery During the COVID-19 Pandemic". JAMA 324.7 (2020): 705.

12. World Birth Rate 1950-2021.
13. Denmark Birth Rate 1950-2021.

14. Netherlands Birth Rate 1950-2021.

15. Ireland Birth Rate 1950-2021.

16. U.K. Birth Rate 1950-2021.

17. Pakistan Birth Rate 1950-2021.

18. Cobo Teresa., et al. "Risk Factors for Spontaneous Preterm Delivery". International Journal of Gynecology and Obstetrics 150.1 (2020): 17-23.

19. Atalan Abdulkadir. "Is the Lockdown Important to Prevent the COVID-19 Pandemic? Effects on Psychology, Environment and Economy-Perspective". Annals of Medicine and Surgery 56 (2020): 38-42.

20. Ali Mohsin., et al. "Analysis and Prediction of the COVID-19 Outbreak in Pakistan". Journal of Biological Dynamics 14.1 (2020): 730-747.

21. Muhaidat Nadia., et al. "Pregnancy During COVID-19 Outbreak: The Impact of Lockdown in a Middle-Income Country on Antenatal Healthcare and Wellbeing". International Journal of Women's Health 12 (2020): 1065-1073.

22. Riley., et al. "Estimates of the Potential Impact of the COVID-19 Pandemic on Sexual and Reproductive Health In Low- and Middle-Income Countries". International Perspectives on Sexual and Reproductive Health 46 (2020): 73.

23. Millions of pregnant mothers and babies born during COVID-19 pandemic threatened by strained health systems and disruptions in services - UNICEF.

\section{Assets from publication with us}

- Prompt Acknowledgement after receiving the article

- Thorough Double blinded peer review

- Rapid Publication

- Issue of Publication Certificate

- High visibility of your Published work

Website: www.actascientific.com/

Submit Article: www.actascientific.com/submission.php

Email us: editor@actascientific.com

Contact us: +919182824667 